\title{
Fracture analysis of AA6061-graphite composite for the application of helicopter rotor blade
}

\author{
Saleemsab Doddamani \\ Department of Mechanical Engineering, Jain Institute of Technology, Davangere, India. \\ saleemsabdoddamani@gmail.com, bttps:/ / orcid.org/0000-0002-8498-1488
}

\section{Chao Wang}

Department of Mechanical Engineering, The University of Texas, Dallas, USA, wowangcha083@gmail.com, https:/ / orcid.org/0000-0002-6668-704X

\author{
M.JinnahSheik Mohamed \\ Department of Mechanical Engineering, Shinas College of Technoogy, Muscat, Oman \\ jinnah.mohamed@shct.edu.om, https://orcid.org/0000-0002-8499-501
}

\section{Md. ArefinKowser \\ Department of Mechanical Engineering, Dhaka University of Engineering and Technology, Garipur, Bangladesh arefin@duet.ac.bd}

\begin{abstract}
The main objective of the work is to study the fracture behavior of AA6061-graphite material using both experimental technique and finite element simulation by considering helicopter rotor blade as a case study. From the case study, it has been observed that the helicopter rotor blade, made of AA6061, has been failed at the threaded portion of the hole. Experimental fracture toughness is carried out using the compact tension specimens as per ASTM standard testing procedure. Modeling of compact tension specimens and the threaded portion of the bolt hole was utilized to analyze the fracture toughness using a simulation tool. From the results and the comparison, it is recommended to use AA6061-9 $\mathrm{wt} \%$ graphite material as a replacement of AA6061 in the application of main rotor blades of the helicopter.
\end{abstract}

KEYWORDS. Metal matrix composite; Al-graphite composite; Simulations; Fracture toughness; Rotor blade.

\section{OPEN ACCESS}

Citation:Doddamani, S., Wang, C., Jinnah, M.S.M., ArefinKowser, Md., Fracture analysis of AA6061-graphite composite for the application of helicopter rotor blade,Frattura ed IntegritàStrutturale, 58 (2021) 191-201.

Received: 26.05 .2021

Accepted: 26.07 .2021

Published: 01.10.2021

Copyright: (C) 2021 This is an open access article under the terms of the CC-BY 4.0, which permits unrestricted use, distribution, and reproduction in any medium, provided the original author and source are credited. 


\section{INTRODUCTION}

$\mathrm{T}$ he property of material through which it is capable of resisting the propagation of crack [1] is known as fracture toughness. Many experimental measurement methods and standardized fracture toughness testing techniques were utilized to cherecterize the material, performance evalutionand also quality assurance of various engineering structures. Thus the fracture toughness determination and testing plays the vital role in the development of fracture mechanics and their applications. The American society for testing and materials (ASTM) provides the standard method for fracture toughness testing and evaluation and also its terminology. One of those methods were ASTM E1823 [2]. The first fracture toughness testing for metallic materials was ASTM E399 [2] which is developed to determine the plain strain fracture toughness $\mathrm{K}_{\mathrm{Ic}}$.

The ASTM E399 can also be applied to the disconitusly reinforced or particulate reinforced metal matrix composites (MMCs). These composites nearly exhibits the isotropic properties [3] whereas the fiber aligned MMCs are highly anisotropic. Some of the particulate reinforcements used were ceramic particles such as silicon carbide, alumina, graphite, boron carbide, titanium carbide etc.

Many experimentation techniques have been conducted [4] on the fracture toughness of the Al6061-graphite particulate composites. Also the comparison of the fracture toughness values of $\mathrm{Al}-\mathrm{SiC}$ and $\mathrm{Al}$-graphite composites has been carried out. From the results it is observed that the Al-graphite particulate composites exhibits the better fracture toughness, light weight, wear resistant, higher coefficient of friction and ductility than the other metal matrix composites. Thus the Algraphite composites can be utilized for the many automobile and aerospace composites. The Al6061 T6 is used in the many applications like bycycle frames and components, wings and fuselages of aircrafts, helicopter rotor blade, etc.

Many authours [5-9] ware studied the failure of helicopter. Literature shows that failure of helicopter occurred is at the threaded hole region of rotor blade. Many helicopter rotor blades are failed due to the fatigue loading, corrosion of threaded holes [5-6]. Litreatures also shows that many helicopter failures occurred in air i.ein the operational conditions [5-7]. Crack developed and propagated, in the rotor blade fittings i.e bolt hole [6,8], edge spar [7] without giving any prior indication. Many researchers reported that main rotor blades are made of aluminum 6061-T6 alloy [5-9].

Mikael Amura et al [5] investigated rescue military helicopter crash in Italy in the oprating conditions. Their investigation revealed that the crash was caused by the fatigue failure of the spar of a main rotor blade. Among five rotor blades, four blades are found in the crash site whereas fifth blade found at a distance of about $900 \mathrm{~m}$ from the crash site. From the investigation it was found that failure of blade happened while helicopter is in the air. Main rotor blade was made of 6061 T6 aluminum alloy. Dr Arjen Romeyn [6] also reported that failure of one of the rotor blades of Robinson R22 helicopter. Failure of the blade occurred at the section of root fitting. Material of the rotor blade is aluminum alloy. Surise helicopters inc [7] investigated the failure of main rotor blade of Bell 206L helicopter, Canada. Material used in the rotor blade is aluminum alloy. The blade fracture was intiated at on the inner surface of the spar, at the location of the void in the adhesive used to bond the lead weight to the spar at station.

Rolf Kieselbach et al [8] studied the failure of a helicopter rotor. Experiments have been conducted to find the material properties. From the result, it is suggested a proposal to detect the cracks before they reach to a critical size. SylwesterKłysz et al [9] also reported the faulire of main rotor blade of the Mi-8 helicopter. Blades of the Mi-8 helicopter are made of 6061-T6 aluminum alloy. Also conducted the strength and fatigue tests of the material of the helicopter blades. Experiments have been carried out to find the strength and fracture characteristics of the material from the main rotor blades of Mi-8 helicopter. Specimens used are disk-shaped compact specimen (DCT) per ASTM standards Fatigue crack growth experiments have been carried out and found that threshold fracture toughness $\Delta \mathrm{K}_{\mathrm{Ic}}$ as 1.34 to $2.81 \mathrm{MPa} \mathrm{V}_{\mathrm{m}}$. Yasmin et al [10], S Doddamani et al [11] worked on aluminum matrix reinforced with graphite particles has been studied for the mechanical and fracture characteristics of the composite respectively. ASTM has prescribed compact tension specimen for the fracture toughness testing [12]. S Doddamani et al [13] uses compact tension specimen to study the fracture toughness of Al6061-graphite MMC at varied weight fractions. K.K. Alaneme et al [14] studied the fracture toughness of Al6063-SiC particulate MMC. It is observed from the results of the fracture toughness testing of Al6061graphite [15] and A16063-SiC [16] that A16061-graphite composite has more fracture toughness values. Different authors [15-21] studied the different methods of the finite element techniques to determine the mechanical/fracture behavior of the materials.

Experimental techniques on prototype provide information concerning the structure in the pattern of the experiment only. Whereas predicting the dynamic behavior of the structure, under different boundary conditions \& loading, can be done by finite element models, but the reliability of the finite element model (FEM) is often not guaranteed. To verification and optimization of these FEM analysis results can be accomplished by the experimental data. The outcome of a model updating examination is a FEM technique that is more reliable for further prediction. FEM software, like 
ANSYS, solves the issues related to structural and mechanical. Structural and mechanical issues incorporate static/dynamic, heat transfer \& fluid problems, linear \& nonlinear structural analysis, and additionally electromagnetic and acoustic issues.

Many two dimensional, three dimensional tutorials ware also available to evaluate the fracture toughness [22-24] using finite element methods, most of them ware used ANSYS tool for the same. While simulating the fracture related issues, it requires the use of PLANE182, which will fit the crack tip section. PLANE182, as shown in Fig 1, is a higher order form of the 2-D, eight-node component. It gives more exact outcomes to blended (quadrilateral-triangular) automatic meshes and can hold up under sporadic shapes without as much loss of accuracy. The 8-node components have ideal displacement shapes and are appropriate to model curved boundaries.

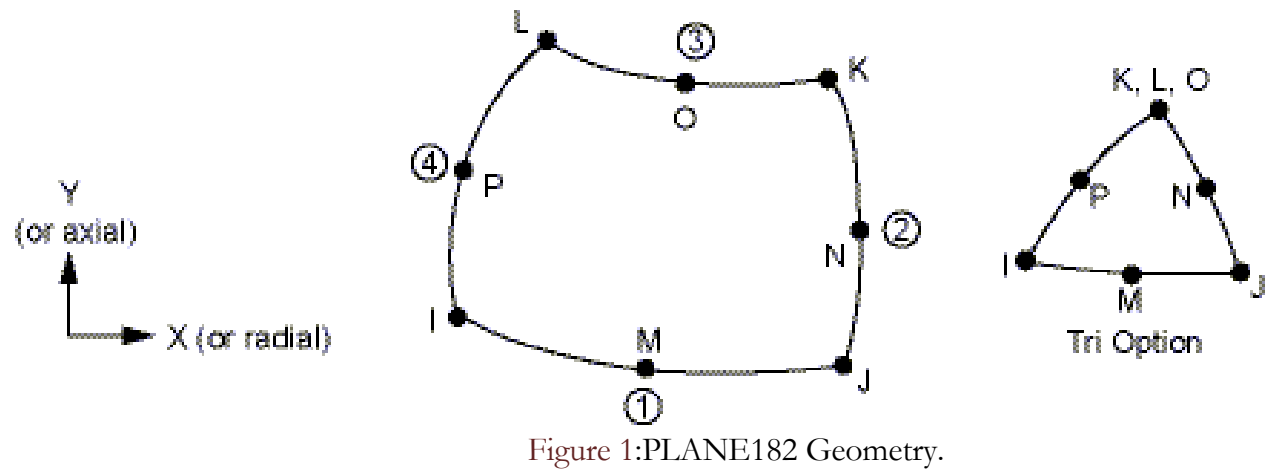

The 8- node component is characterized by eight nodes having two degrees of freedom at every node: interpretations in the nodal $\mathrm{x}$ and $\mathrm{y}$ directions. The component might be utilized as a plane component or as an axis-symmetric component. The component has stress stiffening, large deflection, plasticity, creep, swelling, and extensive strain abilities. The stress intensity factors at a crack for a linear elastic fracture mechanics analysis may be computed. The analysis uses a fit of the nodal displacements in the vicinity of the crack.

From the literature it is identified the helicopter rotor blade, made of AA6061, was failed at the threaded portion of the rotor blade. The main objective of the work is to study the fracture behavior of AA6061-graphite material using both experimentation and finite element simulation method by considering helicopter rotor blade as a case study. The finite element model is built for the AA6061 and AA6061-graphite composite. Through this work an attempt has been made to compare the existing use of material with the composite material to prepare the helicopter rotor blade so as to enhance its fatigue crack resistance property.

\section{MATERIALS}

A luminum alloy (AA) 6061 and its main alloying elements are silicon (0.70\%) and magnesium (0.81\%). Physical properties [25] of AA6061 were hardness $95 \mathrm{BHN}$, elastic modulus $68.9 \mathrm{GPa}$, ultimate tensile strength $315 \mathrm{MPa}$, yield strength $275 \mathrm{MPa}$, extension $17 \%$. Graphite is available in the shape of fibers and particles which has been identified as high strength material. Physical properties of graphite [26] are elastic modulus $15 \mathrm{GPa}$, yield strength 119 $\mathrm{MPa}$, Thermal Expansion Coefficient is $8.2 \times 10^{-6^{\circ}} \mathrm{C}$. Out of many factors which influence the fracture properties, the particle size of graphite is most important microstructural variable. AA6061 and graphite particulate metal matrix composites produced by solidification techniques presents better mechanical properties which can be potential materials for aerospace and automobile applications [27-30].The mechanical properties of the AA6061-graphite composites used for this study are listed in the Tab. 1.

\begin{tabular}{llcccc}
\hline Sl.No & \multicolumn{1}{c}{ Specimens } & $\begin{array}{c}\text { Yield strength } \\
(\mathrm{MPa})\end{array}$ & $\begin{array}{c}\text { Ultimate tensile } \\
\text { strength }(\mathrm{MPa})\end{array}$ & $\begin{array}{c}\text { Percentage } \\
\text { Elongation }\end{array}$ & $\begin{array}{c}\text { Elastic } \\
\text { Modulus } \\
(\mathrm{GPa})\end{array}$ \\
\hline 1 & AA6061 & 85.6 & 102.4 & 16.8 & 68.9 \\
2 & AA6061-6wt $\% \mathrm{SiC}$ & 93.3 & 114.1 & 14.1 & 65.6 \\
3 & AA6061-9 $\mathrm{wt} \% \mathrm{SiC}$ & 99.1 & 117.3 & 14.3 & 64.2 \\
4 & AA6061-12 $\mathrm{wt} \% \mathrm{SiC}$ & 98.9 & 115.8 & 13.7 & 64.4 \\
\hline
\end{tabular}

Table 1:Mechanical properties of AA6061-graphite composites 


\section{METHODS}

\section{Experimentation}

7 he compact tension (CT) specimen is used to test the fracture toughness as per the ASTM E399 standard testing procedures. The geometry of the specimen is as shown in the Fig $2(a)$. The crack length to width $(a / W)$ ratio considered is 0.45 , width of the specimen considered is $40 \mathrm{~mm}$ and thickness of the specimen is $12 \mathrm{~mm}$ which confirms the conditions $[12-13,28]$ of plane strain fracture toughness. The experimentation has been carried out using servo hydraulic testing machine by maintaining the frequency of $5 \mathrm{~Hz}$ and displacement rate $1 \mathrm{~mm} / \mathrm{min}$.

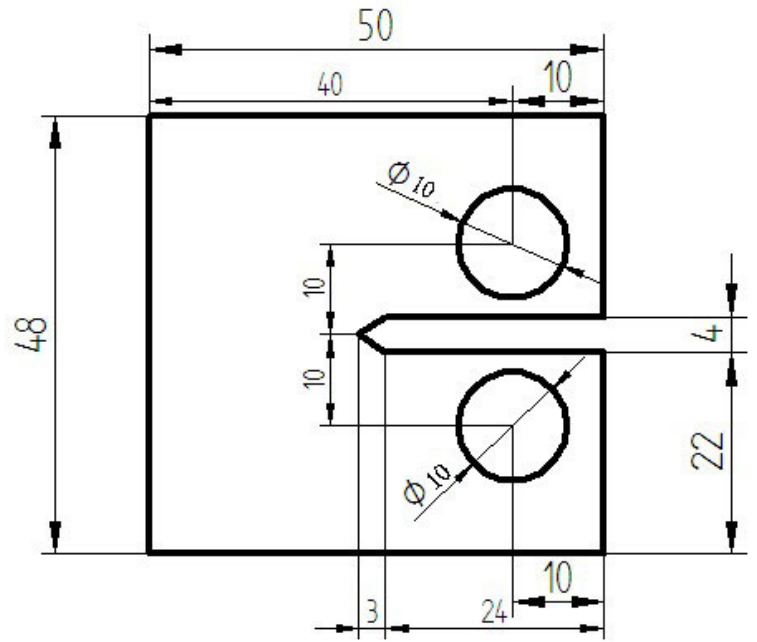

Figure 2(a): Geometry of the CT specimens.

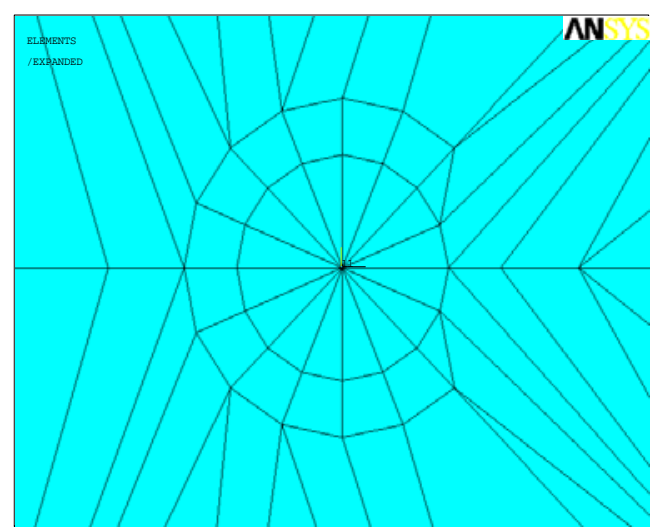

(a)Full Crack Model

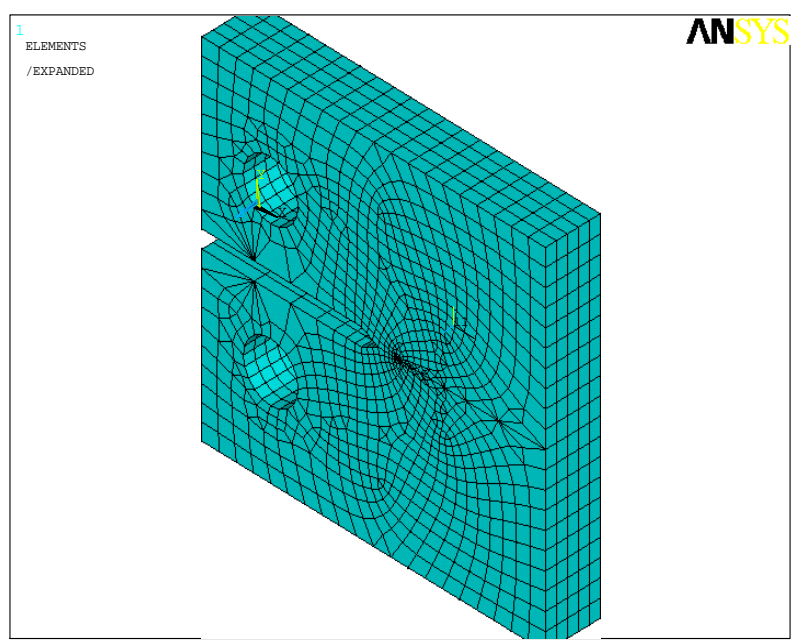

Figure 2(b): Finite Element Model

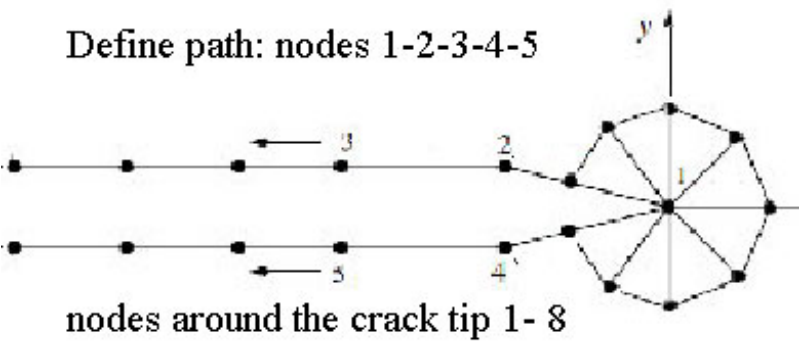

(b) Nodes around the crack tip

Figure 3: Crack tip region.

\section{Model Generation}

Using ANSYS, the geometric model was created. A finite element model was constructed utilizing PLANE182 and SOLID185 components shown in Fig 2(b). The nodes around the crack tip appear in Fig 3. Von Neumann's method is used, which is the most widely used approach, to study the stability of numerical schemes. It is not necessary to refine the mesh of the entire model. From the Saint-Venant's Principle, the model can be refined at the regions of interest. Thus the coarse element sizes are refined at the crack tip to the fine mesh. The mesh refinement at the crack tip leads to reduction 
of errors significantly. From the mesh refinement, the convergence of solutions can be increased without an increment in the problem size it can be solved.

The singularity, in fracture mechanics, is essential. At the crack tip, there is the small localized plastic zone will be formed due to the higher stresses at that region. Crack tip is the sharp corner which causes the worst conceivable geometrical singularity. In the singularity region the stresses become infinite. It is difficult to compute the stress field in finite element simulations because of the singularity. However it is not necessary to investigate the details of crack tip. There are direct approaches to determine the fracture toughness of the material. Since these approaches determine the global quantities far from crack, the singularity can be ignored.

The finite element model was built using PLANE182 element [31], for the crack analysis of the aluminum-graphite alloy. The crack analysis was carried out and the resulting analysis is shown in Tab. 1.

\section{FAILURE OF A HELICOPTER MAIN ROTOR BLADE}

A rescue military helicopter crashed in the middle of a ferry flight towards an air terminal where an activity was planned. All team individuals endured fatal injuries [5-7]. The rescue military helicopter suddenly changed direction, and lost control due to the detachment of one of the rotor blades. The increase of fatigue crack growth reduces the strength of the blade to an extent that allowed the fracture to occur under normal flight loads. In view of the direction of failure of the helicopter, the Safety Investigation Board found part of the failed blade separated around $900 \mathrm{~m}$ before the disaster area. The failure analysis of the fractured blade was conducted and it was determined that part of the blade detached in the air due to which helicopter become uncontrollable. The main rotor blade is about $9 \mathrm{~m}$ long. The structural part of the blade is made of 6061-T6 aluminum alloy [5-8] and were $4.5 \mathrm{~mm}$ thick on average.

The observations demonstrated various initiation points along an cut on the external and internal surface. Blade fracture happened because of the initiation of a fatigue crack in the bolt hole in the blade spar to root fitting joint. Fig 4 shows the root fitting of the blade, an aluminum alloy that accommodates the blade spindle and bearings, had fractured at the innermost bolt hole of the root fitting to blade spar joint.

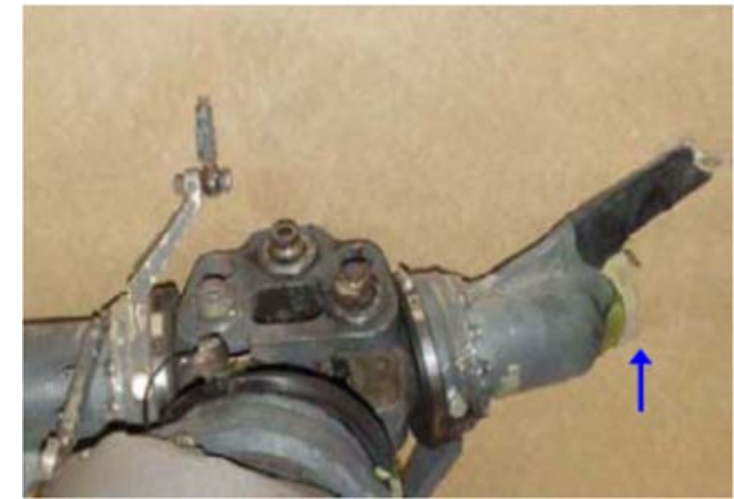

Figure 4(a) recovered main rotor head assembly [6]

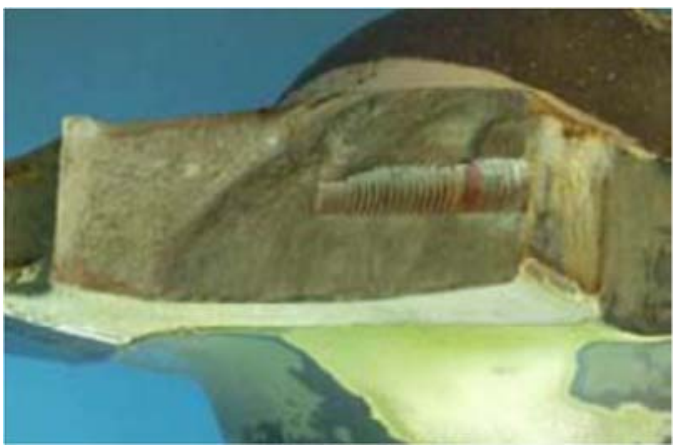

Figure 5(a) Fitting side, or inboard side, of the fracture [6]

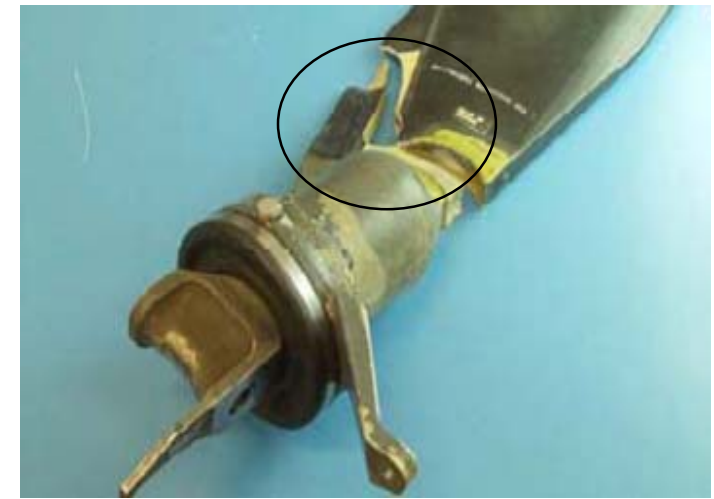

Figure 4 (b) fractured main rotor blade [6]

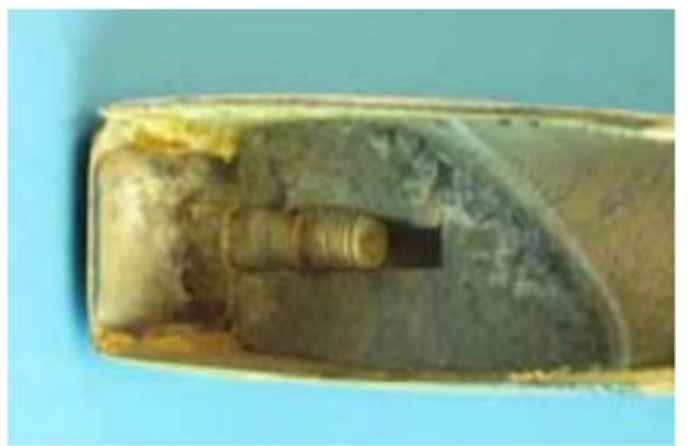

Figure 5(b) The blade side, or outboard side, of the fracture [6] 

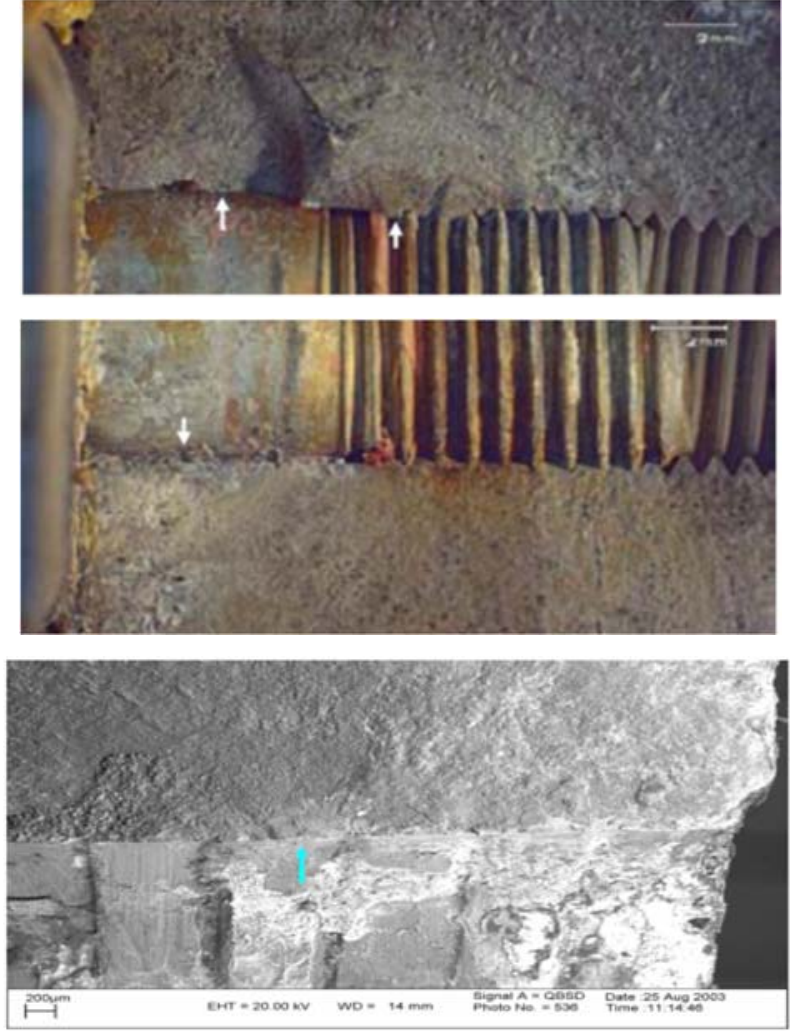

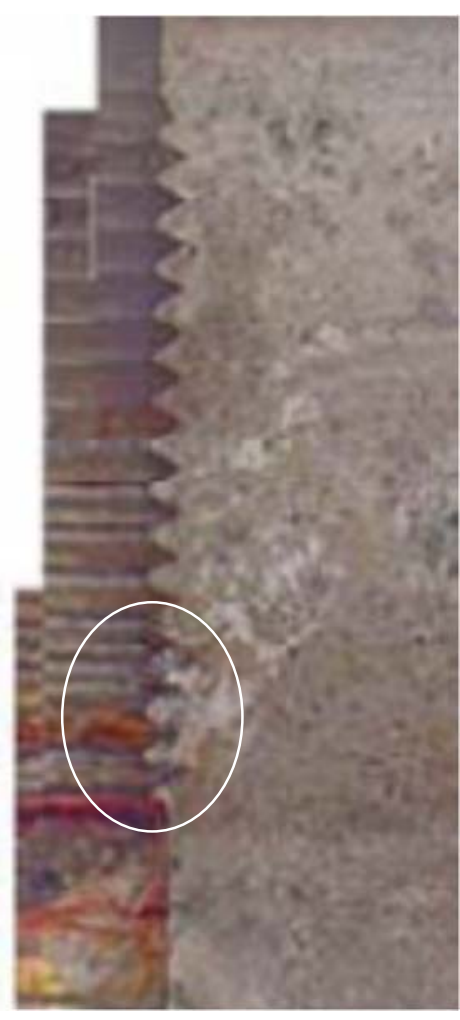

Figure 6: Sites of fatigue crack initiation (arrowed) [6].

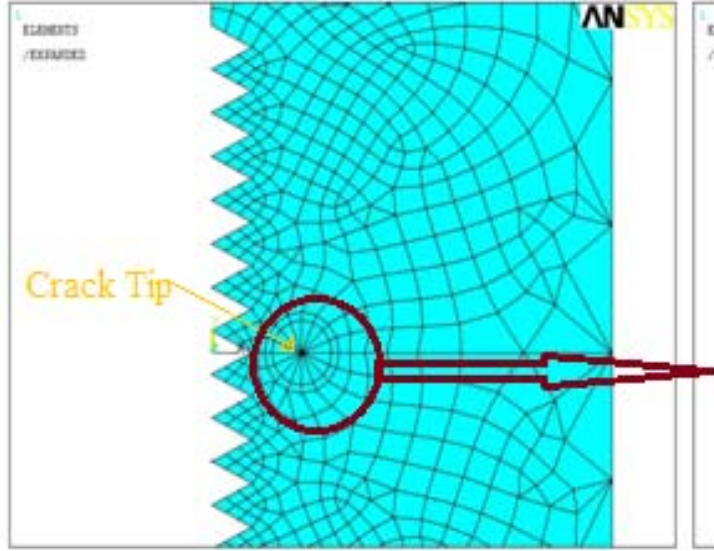

Figure 7(a) FEA Model

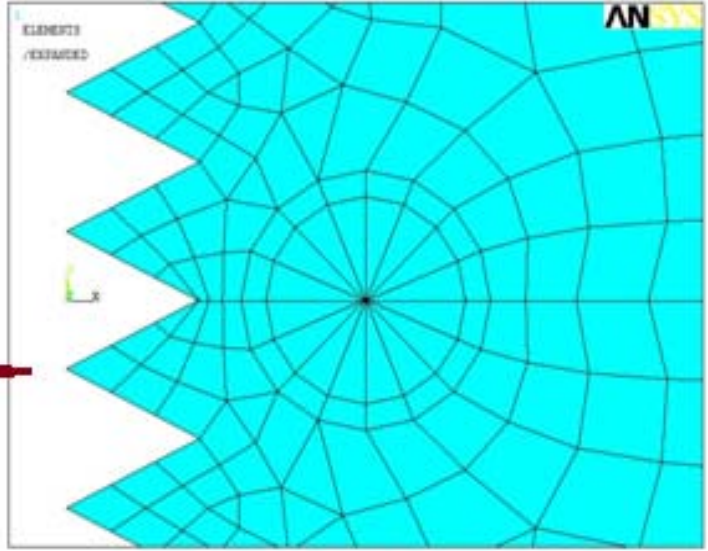

Figure 7(b) FEA nodes around the crack tip

From the Fig 5(a), (b) it is observed from the fracture surface features that fracture take place as a result of the progressive crack growth from the inboard bolt hole. The fatigue crack growth mechanism was used, i.e., crack initiation and crack propagation in response to the development of repeated alternating stresses throughout the operation.

Due to the failure of the adhesive bond (disbonding) at the bolt hole, failure of the main rotor blade occurs. The disbonding take place at spar end, and the root fitting of upper and lower blade skins as shown in Fig 5.

From Fig 6, it is clear that moisture reacted with the crack surfaces. Followed by localized corrosion occurred in the counterbore (Fig $6(\mathrm{~b}, \mathrm{c})$ ). The nature of crack propagation marks signifies that fatigue crack initiation occurred at (a) the lower side of the bolt hole, (b) the thread on the upper side of the bolt hole and (c) the counterbore on the upper side of the bolt hole. From Fig 6 it is evident that the failure of the rotor blade occurred at the bolt hole and threaded portion of the bolt hole. 
The FEM model to find the fracture toughness is created using ANSYS. A structural model was created using an 8-node PLANE182 element with no real constants values. For the element PLANE182, the area has been created with a concentrated key point at the crack tip. The model was meshed, gave symmetric boundary conditions and loads applied before solving the problem. The finite element model is built using PLANE182 elements, crack tip and nodes around the crack tip are shown in Fig 7.

ANSYS, there is no possibility of voids, clustering of reinforcements, particle and matrix interfaces; material will not have any other crack in its structure. Since the fracture toughness depends on the material properties (Tab. 1), crack length and the load at fracture (Pf), nearly better results will be obtained as compared to experimental results.

\section{RESULTS AND Discussions}

he fracture toughness of the AA6061 and AA6061-graphite composites has been carried out, both experimental and 3D simulations, using CT specimens and threaded portion of the AA6061 and AA6061-graphite composites using finite element simulations. The result of the analysis has been given in the Tab. 2 .

\begin{tabular}{|c|c|c|c|c|}
\hline \multirow[b]{2}{*}{ Sl No } & \multirow[b]{2}{*}{ Composite } & \multicolumn{3}{|c|}{ Fracture Toughness $\left(\mathrm{K}_{\mathrm{Ic}}\right) \mathrm{MPa} \sqrt{\mathrm{m}}_{\mathrm{m}}$} \\
\hline & & Experimental & $\begin{array}{c}\text { Simulation of CT } \\
\text { specimen }\end{array}$ & $\begin{array}{c}\text { Simulation of Threaded } \\
\text { portion }\end{array}$ \\
\hline 1 & AA6061 & 15.45 & 15.34 & 15.94 \\
\hline 2 & AA6061-6\%graphite & 16.22 & 16.42 & 17.21 \\
\hline 3 & AA6061-9\% graphite & 16.74 & 18.73 & 18.28 \\
\hline 4 & AA6061-12\% graphite & 15.70 & 17.64 & 17.98 \\
\hline
\end{tabular}

Table 2: Fracture Toughness results of AA6061 \& AA6061-graphite composites.

The experimental fracture toughness of the AA6061-graphite composites has been carried out for the different weight fractions of the graphite. For each composition, three CT specimens were prepared and tested. The mean value of the fracture toughness has been listed in the Tab.2. The fracture toughness with increment in the graphite percentage has been plotted as shown in the Fig 8. Specimens of unreinforced Al6061 exhibits the lesser deviations for the samples tested. However, the samples AA6061-6wt $\%$ and $9 \mathrm{wt} \%$ graphite shows the similar deviation whereas the AA6061$12 \mathrm{wt} \%$ graphite have the increased deviation than others. This larger deviation is may be due to the difference in the fracture toughness values among the specimens tested. Also as the graphite composition increases the fracture toughness increases up to $9 \mathrm{wt}^{\%} \%$ of graphite and later decreases at $12 \mathrm{wt} \%$ of graphite. This decrement is due the increase of reinforcement decreases the ductility, thus decreases the fracture toughness of the said composite.

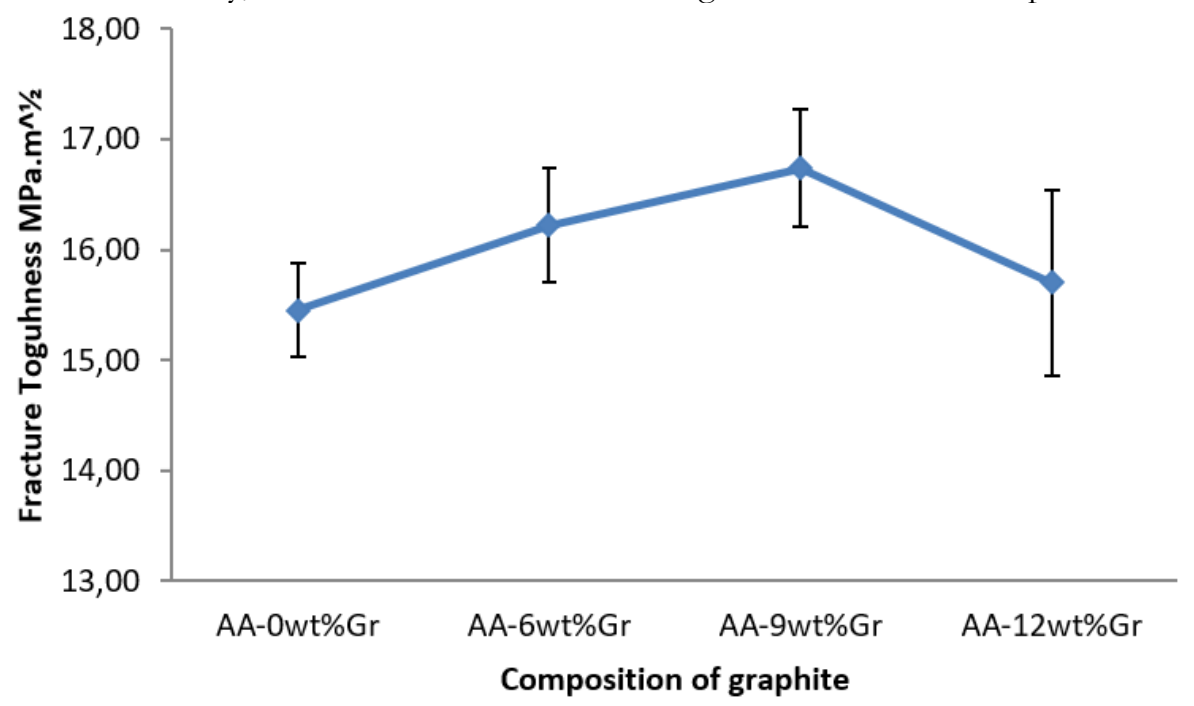

Figure 8: Fracture toughness of the AA6061-graphite composites. 
From the Tab. 2 it is observed that the fracture toughness values are almost near to each other. However the FE simulation results are higher than the experimental results. This is due to the fact that only one crack has been introduced in the simulation model whereas in the experimental specimen there may be many voids, dislocations and micro-cracks were available leads to the reduction in the fracture toughness.

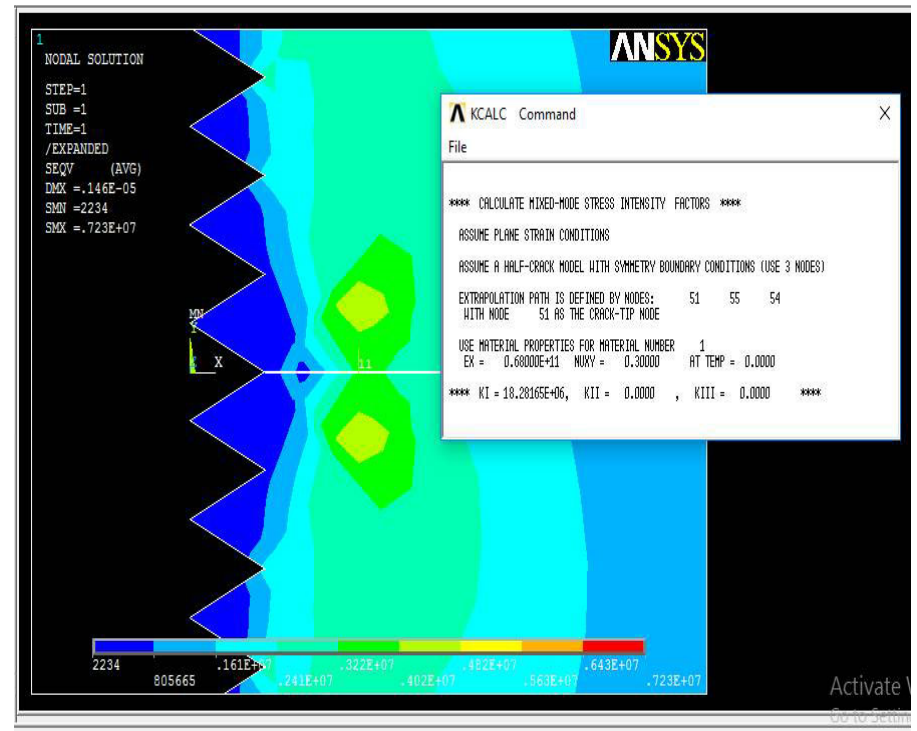

Figure):Stress concentration factor K1 of AA6061-9\%graphite for rotor blade.

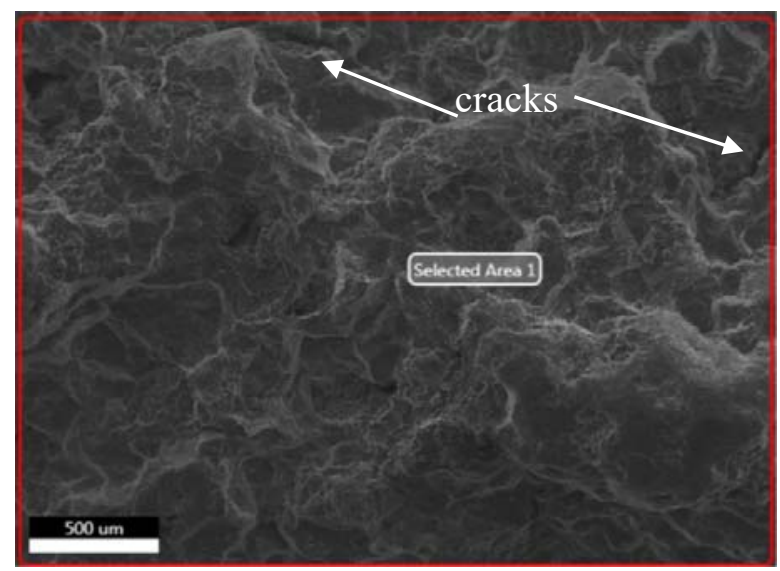

(a) Unreinforced Al6061 alloy

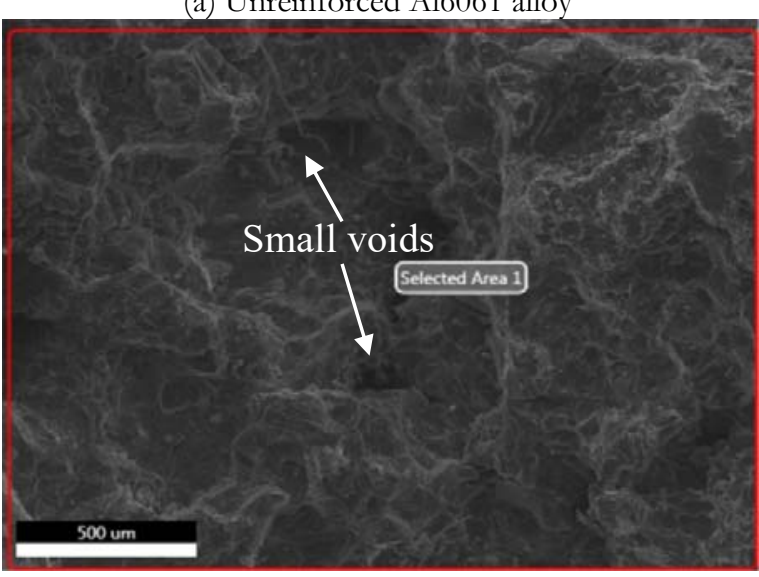

(c) $\mathrm{Al} 6061-9 \mathrm{wt} \%$ of $\mathrm{SiC}$

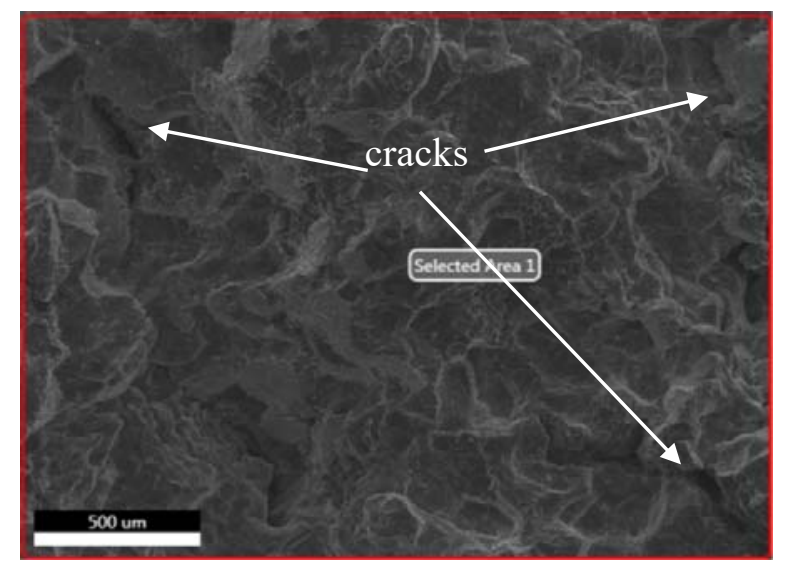

(b) $\mathrm{Al} 6061-6 \mathrm{wt} \%$ of $\mathrm{SiC}$

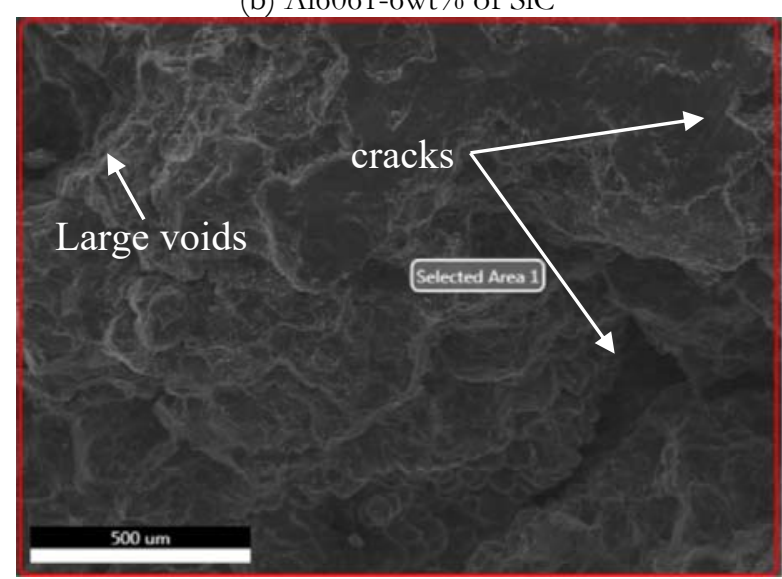

(d) $\mathrm{Al} 6061-12 \mathrm{wt} \%$ of $\mathrm{SiC}$

Figure 10. SEM Fractographic images 
Fig 9 shows the fracture toughness value of the AA6061 with $9 \mathrm{wt} \%$ graphite particles and also shows the shape of the plastic zone. The shape of the plastic zone obtained indicates the plane strain fracture toughness [1]. The fracture toughness of the AA6061 with $9 \mathrm{wt} \%$ graphite composite exhibits the higher values. Thus it is considered to be the better composition of the composite among tested. From the above results it is recommended that AA6061-9\%graphite material can be considered as a potential rotor blade material as a replacement of AA6061 in the application of main rotor blades of the helicopter.

Fig10 shows the fractographic images of the Al6061-graphite composites obtained through the SEM. Fractographic images shows the formation of cracks at the unreinforced aluminum alloy and at $6 \mathrm{wt} \%$ of graphite whereas at the $9 \mathrm{wt} \%$ of graphite have the smaller voids which transforms into the cracks on loading. Thus the increased fracture toughness has been observed. The decrement in the fracture toughness after the $9 \mathrm{wt} \%$ graphite, is due to increased hardness and increased crack initiation sites and reduced ductility.From the Fig. 9 it is also observed that, all the Al-graphite composites exhibits the dull and fibrus surface. Which means that the said composites have the ductile fracture. Thus the increased fracture toughness of the Al-graphite composite is the addition of graphite reinforcement. However the increment in other reinforcements such as $\mathrm{SiC}[14]$ in the aluminum composites exhibits the lesser ductility and fracture toughness values.

\section{CONCLUSIONS}

he failure of the helicopter rotor blade occurred at the threaded portion of the bolt hole. The finite element model of the bolt hole and the compact tension specimen was successfully modeled using the ANSYS. The fracture toughness values obtained from the FE simulation are in close agreement with data obtained from standard $\mathrm{K}_{\mathrm{Ic}}$ testing. From the comparison of experimental and the FE simulation results, it is recommended that AA6061-9\%graphite material can be considered as a potential rotor blade material as a replacement of AA6061 in the application of main rotor blades of the helicopter.

\section{FUNDING}

7 his research received no specific grant from any funding agency in the public, commercial, or not-for-profit sectors.

\section{CONFLICT OF INTEREST}

he authors declare that they have no conflict of interest.

\section{REFERENCES}

[1] Anderson, T .L., (2013). Fracture Mechanics-Fundamentals and Applications. 3rd Edition, Taylor \& Francis Group, New York.

[2] Zhu, X.K., Joyce, J. A., (2012) Review of fracture toughness (G, K, J, CTOD, CTOA) testing and standardization, Engineering Fracture Mechanics, Elsevier, 85, pp.1-46. https://doi.org/10.1016/j.engfracmech.2012.02.001

[3] ASM Handbook. (2001) Composites, 21, ASM International.

[4] Doddamani, S. and Kaleemulla, M. (2019). Comparisons of experimental fracture toughness testing methods of Al6061-graphite particulate composites, Journal of Failure Analysis and Prevention, Springer, 19(3), pp.730-737. DOI: $10.1007 /$ s11668-019-00652-8.

[5] Amura, M., Aiello, L., Colavita, M., Paolis, F.D., Bernabei, M. (2014). Failure of a helicopter main rotor blade, 20th European Conference on Fracture (ECF20), Procedia Materials Science, 3, pp.726 - 731. 
[6] Romeyn, A., (2005). Main rotor blade failure analysis report, Engineered system failure analysis report.

[7] Sunrise helicopter Inc, (2011). In-flight separation of Main Rotor Blade and Collision with Terrain, Aviation Investigation Report, A11O0205.

[8] Kieselbach, R., Soyka, G., (2000). Failure of a helicopter rotor, Technology, Law and Insurance, T and F Online, 5,(34), pp.141-146.

[9] Klysz, S., Lisiecki, J., Kurdelski, M. (2010). Material testing of the helicopter main rotor blades, 37th Solid Mechanics Conference, September.

[10] Yasmin, B., Doddamani, S. (2015). Mechanical Properties of Aluminium-Graphite Particulate Composites, NCERAME-2015, International Journal of Engineering Research \& Technology (IJERT), pp.121-124.

[11] Doddamani, S. and Kaleemulla, M. (2016). Indentation Fracture Toughness of Alumnum6061-Graphite Composites, International Journal of Fracture and Damage Mechanics, 1(1), pp. 40-46.

[12] ASTM Standards, (2017). Standard Test Method for Plane-Strain Fracture Toughness of Metallic Materials, ASTM International, E 399-17.

[13] Doddamani, S., Kaleemulla, M. (2017). Fracture toughness investigations of Al6061-Graphite particulate composite using compact specimens, Frattura ed IntegritàStrutturale, 41, pp.490-497. DOI: 10.3221/IGF-ESIS.41.60

[14] Alaneme, K.K., Aluko, A.O. (2012). Fracture toughness (K1C) and tensile properties of as-cast and age-hardened aluminium (6063)-silicon carbide particulate composites, Scientia Iranica A, 19 (4), pp 992-996.

[15] Allegrucci F .L., Paolis A.D. Coletta M. Bernabei, (2013). Crack of a helicopter main rotor actuator attachment: failure analysis and lessons learned, Frattura ed IntegritàStrutturale, 26, pp.104-122; DOI: 10.3221/IGF-ESIS.26.11

[16] Henkel, S., Wolf, C. H., Biermann, H., Burgold, A. and Kuna, M., (2019). Cruciform specimens used for determination of the influence of T-stress on fatigue crack growth with overloads on aluminum alloy Al $6061 \mathrm{~T} 651$, Frattura ed IntegritàStrutturale, 13(48), pp.135-143. DOI: 10.3221/IGF-ESIS.48.16.

[17] Chen, G., Huang, X. (2016). Simulation of Deformation and Fracture Characteristics of a 45 Steel Taylor Impact Specimen, Engineering Transactions, 64(2), pp.225-240

[18] Talemi, R.H. (2016). Numerical simulation of dynamic brittle fracture of pipeline steel subjected to DWTT using XFEM-based cohesive segment technique, attura ed Integrità Strutturale, 36, pp.151-159; DOI: $10.3221 /$ IGF-ESIS.36.15

[19] Shlyannikov, V., Yarullin, R., Ishtyryakov, I. (2017). Effect of different environmental conditions on surface crack growth in aluminum alloys, Frattura ed Integrità Strutturale, 41, pp.31-39.

[20] Bharath, K.N., Manjunatha, G. B. (2018). Investigating the contribution of geometrical parameters and immersion time on fracture toughness of jute fabric composites using statistical techniques, Frattura ed Integrità Strutturale, 12(46), pp. 14-24. DOI: 10.3221/IGF-ESIS.46.02.

[21] Dhummansure, V., Kalyanrao, A.A., Doddamani, S. (2020). Optimization of process parameters for fracture toughness of Al6061-graphite composites, Structural Integrity and Life, 20(1), pp 51-55.

[22] Taha, B. B., Benattou, B. and Ghazi, A., (2018). Simulation of the behavior of aluminum alloys welded in Friction Stir Welding FSW: (Case of AA5083 and AA 6082), Frattura ed Integrità Strutturale, 12(46), pp. 1-13.

DOI: $10.3221 /$ IGF-ESIS.46.01.

[23] Seitl, S., Viszlay, V., (2017). Modified compact tension specimen for experiments on cement based materials: comparison of calibration curves from 2D and 3D numerical solutions, Frattura ed Integrità Strutturale, 39, pp. 118128. DOI:10.3221/IGF-ESIS.39.13

[24] Kikuchi, M., Wada, Y., Li, Y. (2015). Crack growth simulation in heterogeneous material by S-FEM and comparison with experiments, Frattura ed IntegritàStrutturale, 34, pp. 318-325; DOI: 10.3221/IGF-ESIS.34.34

[25] Hareesha G., Chikkanna N., Doddamani, S. (2021). Finite Element Simulation of Fracture Toughness of Al6061Reinforced with Silicon Carbide, IOP Conference Series: Materials Science and Engineering, 1065, 012036, pp.1-6. DOI: 10.1088/1757-899X/1065/1/012036.

[26] Doddamani, S. and Kaleemulla, M. (2018). Effect of graphite addition on the fracture and fatigue crack growth behavior of Al6061-Graphite, Structural Integrity and Life, 18(3), pp.185-192.

[27] Doddamani, S. and Kaleemulla, M. (2019). Effect of aging on fracture toughness of Al6061-Graphite particulate composites, Mechanics of Advanced Composite Structures, 6(2), pp.139-146. DOI: 10.22075/macs.2019.16436.1177.

[28] Doddamani, S., Kaleemulla, M. (2017). Experimental investigation on fracture toughness of Al6061-graphite by using Circumferential Notched Tensile Specimens, Frattura ed Integrità Strutturale, 39, pp.274-281.

[29] Doddamani, S. and Kaleemulla, M. (2019). Effect of Thickness on fracture toughness of Al6061-Graphite, Journal of Solid Mechanics, 11(3), pp. 635-643. DOI: 10.22034/jsm.2019.666695. 
[30] Doddamani, S., Kaleemulla, M., Kiran J .O., Bakkappa, B. (2019). Fracture toughness testing of 6061Al-graphite composites using SENB specimens, Journal of The Institute of Engineers (India)-series D, Springer, 100(2), pp.195201. DOI: $10.1007 / \mathrm{s} 40033-019-00188-z$.

[31] Yasmin B., Bharath K .N., Doddamani, S., Rajesh A.M., Mohamed Kaleemulla K. (2020). Optimization of process parameters of fracture toughness using simulation technique considering aluminum-graphite composites, Transactions of the Indian Institute of Metals, Springer, 73(12), pp. 3095 - 3103. DOI: 10.1007/s12666-020-02113-5. 